\title{
Cosmetic Surgery and Body Image in Adolescents: A Psycho-Sociological Analysis of the Causes and Effects
}

\author{
Dr. Merah Souad \\ Assist. Prof \\ Kulliyyah of Education \\ International Islamic University Malaysia \\ Dr. Tahraoui Ramdane \\ Assist. Prof \\ Kulliyyah of Education \\ International Islamic University Malaysia \\ Tahraoui Ghada \\ Medical Student \\ Queen Mary \\ University of London \\ Dr. Mariya Seemin \\ Head of Secondary Section \\ Al Idrissi International School \\ Malaysia
}

\begin{abstract}
This conceptual paper examines the impact of body image on Adolescents' quest for cosmetic surgery. A reflective analysis of the literature was utilized. Factors shaping one's perception of own body was explained .The causes and effects were also highlighted. The study has shown, that there has been a definite increase in the number of teenagers undergoing various cosmetic procedures and that a correlation can be drawn between this quest and poor body image, which could have alarming physical, social and emotional consequences. As for the causes the study has concluded that the quest to achieve a better appearance is mainly due to the socially portrayed "ideal beauty standards". There is a consensus among researchers and medical practitioners that, the main pushing factor towards going under the knife is social especially enhancement procedures. It was also found that; the media and the rigorous capitalist's campaign to boost consumerism is behind the rampant body idealization culture. In addition, the study has also shown that the availability of advanced cosmetic procedures in some countries has led to the increase of adolescents' seeking body modifications.
\end{abstract}

Keywords: Cosmetic Surgery, Body Image, Adolescents, Causes \& Effects

\section{Introduction}

Body image is usually defined as the mental image of one's own body. This image is usually shaped by perception, emotions and physical sensations, as well as all the physiological and emotional changes an individual passes through during the processes of growth and socialization. In this process, all social institutions and agents, such as family, peers, school and the media, play a crucial role in creating this image. In fact, body image is fluid and can change depending on an individual's environment, mood and experiences. Research has shown that passing through puberty can increase one's concerns about his/her body image, with some level of difference between the two sexes. Being overly-concerned with body image can lead people in general and adolescents in particular to look for means to enhance their physical appearance and enable them to conform to dominating trends portrayed by many -particularly the media- outlets. 
One of the extreme alternatives is to opt for cosmetic surgery, which may be due to the absence of proper education and orientation. Living in the age of post-modernism, which brings along with it, developments of different levels such as rapid technological development, the availability of all sorts of products and the high level of consumerism has made the human body a major focus of attention.

Individuals are more concerned than ever about their health, wellbeing, longevity and -very importantly- their physical beauty. The desire to comply with society's idolized stereotype of beauty has become so extreme that women and men of all ages will go to great lengths to achieve that image of perfection, be it by altering their lifestyle through diet, exercise and beauty products, or by taking more drastic measures that include cosmetic surgery. Thus, the issue of body image has become an important subject of study in many different disciplines including Medicine, Nutrition, Psychology, Sociology, etc., and has become one of the hottest controversial issues faced by modern societies.

\section{Body Image and Beauty}

Historically, seeking a beautiful appearance has always been a preoccupation for both men and women across the different societies that have inhabited different parts of the world. It has often been said that beauty is in the eye of the beholder. However, it also has a lot to do with the beholder's cultural standards. In fact, looking for a socially accepted outward appearance has always been a human trait, although what is deemed beautiful and the perceptions surrounding it vary according to one's culture. The common feature is that beauty in general terms is a human aspiration. For instance, "Ancient Egypt was one of the vainest ancient civilizations and one of the first nations that created perfumes, oils and other beauty treatments. Indeed, the Egyptians placed a very high emphasis on their physical appearance." ${ }^{2}$ In ancient Greece, physical beauty was highly venerated as well and those who were deemed beautiful were revered. The history of beauty is really about the history of philosophical and perceptual notions of perfection and how they have been applied to ideas and objects, as well as to the human body ${ }^{3}$ andPlato considered beauty to the Idea (Form) above all other Ideas". 4

It is usually perceived that; seeking beauty is a preoccupation associated with women. However, in recent years, men have become increasingly interested to alter the aspects they do not like to see in the mirror. Nowadays, there is a noticeable increasing demand for cosmetic surgery among women and men equally regardless of age, especially in the developed world where the most sophisticated techniques and procedures are available, as well as possessing a socio-cultural environment that is less hostile towards these practices. Another reason as to why the demand is higher in these countries is simply that individuals are able to pay for the high cost of these procedures.

Though researchers are keen to differentiate between "Real self (actual or objective self) - the way the person actually is, 2. Self-image (subjective self) - the way a person sees herself or himself, 3. Ideal self (selfactualization) - the way she or he would like to be, 4. Looking-glass self (social self) - the way she or he thinks others regard her or him," own mind), is the prevalent reason behind seeking cosmetic surgery in both genders, and both women and men regardless of age are attracted to cosmetic surgery procedures to modify body looks for either reconstruction or enhancement. Teenagers currently are not exempt from this phenomenon either. Thus, it is crucial to look into the real reasons behind such decisions, in addition to understanding their socio-cultural and economic background and the type of cosmetic surgery they opt for, as well as taking into considerations the objectives they want to achieve.

\section{What is Body Image?}

The German writer Schilder first formulated the concept of 'body image' as an important and integral phenomenon in 1935.

\footnotetext{
${ }^{1}$ Umberto Eco, History of Beauty. Rizzoli International Publications, Incorporated, 2010

${ }^{2}$ The Concept of Beauty in Ancient Egypt.Retrieved from: http://www.ancientfacts.net/the-concept-of-beauty-in-ancientegypt/ . Date: [6/2/2018]

${ }^{3}$ Umberto Eco. Ibid

${ }^{4}$ Phaedrus by Plato.Retrieved from http://sfbay-anarchists.org/wp-content/uploads/2013/07/Plato-Phaedrus.pdf . Date:[6/2/2018]

${ }^{5}$ On visit, S., \& Shaw, J. (1987). Self-concept and image congruence: Some research and managerial implications. Journal of Consumer Marketing, 4, 13-23. Pg. 17

130
} 
Recent literature, which is greatly shaped by applied clinical concerns, has expanded on this idea by explaining that 'body image' has been greatly influenced by specific 'neurological disorders' in which patients exhibit a faulty perception of their own body image, body image distortion (BID) and delusional misperception. ${ }^{6}$

It is also defined as the mental representation one creates about his looks, but it may or may not bear close relation to how others actually see you. Body image is subject to all kinds of distortion from internal elements such as our emotions, moods, early experiences, attitudes of our parents, and much more. Nevertheless, it strongly influences behaviour. Preoccupation with and distortions of body image are widespread among women in particular and, to a lesser extent, among males. ${ }^{7}$

Charles Horton Cooley (1902), has coined the concept of the 'looking-glass', in which he claims that, the development of one's self and of one's identity is materialized through one's interpersonal interactions within the context of society. This means that one's definition of self contains "definite imagination of how one's self appears in a particular mind, particular mind of others." 8

\section{Why Cosmetic Surgery?}

"Cosmetic surgery" is used in reference to the ability of surgeons to reshape the appearance of the human body parts through special techniques in order to improve their appearance. It is known among the plastic surgery practitioners that plastic surgery has two branches: cosmetic surgery, which aims to improve the aesthetic appearance of a person, and reconstructive plastic surgery, which aims to restore the function; however, it may also involve correcting the deformities to normalize the appearance, but that is not its primary function. ${ }^{9}$ Thoughthe roots of cosmetic surgery- the reconstructive type in particular- can be traced back to ancient civilizations -particularly in ancient Egypt, India and other parts of the world-, these medical procedures have become a highly demanded option in the modern world of today, sought by many people of different genders, ages and from all walks of life. Statistics show that more men are going under the knife ${ }^{10}$ due to social and economic transformations in the society. Industrial developed communities in particular place high value on living healthy and looking good, which leads to men and women, young and old, to request cosmetic surgery for aesthetic reasons. Furthermore, the dominance of human rights and freedom helped to wipe away many taboos related to handling one's body especially in western societies. Traditionally, males seeking cosmetic surgery have been considered more psychologically disturbed than their female counterparts. ${ }^{11}$

In an early inquiry by a Japanese research team, it was found that $82.3 \%$ of the male subjects began to be preoccupied with what is perceived to be a 'deformity' between teenage years and early adult lives. ${ }^{12}$ According to Dr. Douglas Steinbrech, a Manhattan-based plastic surgeon, there are four types of men who normally seek maleoriented cosmetic procedures. ${ }^{13}$ First, there is 'the male model' who wants a sharper jawline and nicer abs (defined abdominal muscles).

\footnotetext{
${ }^{6}$ Peter David Slade. (1993). Invited Essay; What is Body Image. Elsevier Science Article. [Internet] 1993 [cited 2016 May 10]. Available at http://www.freepaperdownload.us/1773/Article2888653.htm

${ }^{7}$ Psychology today. Retrieved fromhttps://www.psychologytoday.com/basics/body-image Date:[14/2/2018]

${ }^{8}$ Cooley Charles Horton. Social Class Theory: The Multicultural Readings. Edited by C. Lemert Philadelphia: Westview Press 2010, pg. 189

${ }^{9}$ Christian Nordqvist. What is cosmetic surgery? What is plastic surgery? Article Doctor. [Internet], 2014 Sep 15 [cited 2016 May 10]. Available at www.medicalnewstoday.com/articles/155757.php

${ }^{10}$ American Society of Plastic Surgeons. Men Fuel Rebound in Plastic Surgery: Sizeable Increases in Face Lift and other Surgical Procedures for Men. Doctor Article. [Internet] 2011 Apr 13 [cited 2016 May 10]. Available at http://www.plasticsurgery.org/news/2011/men-fuel-rebound-in-cosmetic-surgery-.html

${ }^{11}$ Michael J. Pertschuk. et al. (1998). Body Image Dissatisfaction in Male Cosmetic Surgery Patients.Aesthetic Plastic Surgery Article. [Internet] 1998 [cited 2016 May 10]. Available at http://download.springer.com/static/pdf/306/art\%253A10.1007\%252Fs002669900160.pdf?originUrl=http\%3A\%2F\%2Flink. springer.com\%2Farticle\%2F10.1007\%2Fs002669900160

${ }^{12}$ Ishigooka,J., Iwao, M., Suzuki, M., Fukuyama, Y., Murasaki, M. and Miura, S. Demographic features of patients seeking cosmetic surgery. Psychiatry and Clinical Neurosciences Article. [Internet] 1998 [cited 2016 May 7]. Available at http://www.ncbi.nlm.nih.gov/pubmed/9681579

${ }^{13}$ Here's Why There's A 'Huge Boom' in Men Getting Plastic Surgery. Business insider Article. [Internet] 2014 [cited 2016 Apr 23]. Available at www.businessinsider,my/male-plastic-surgery-procedures-2014-2/?r=US\&IR=T\#ZYeGsXottTZwqed.97
} 
Second, there is 'the body builder' who seeks out similar procedures as the male model type, but wants to look more muscular and big. Third, there is 'the CEO or board member' who is at the top of his career and feels confident but he is worried he does not look the part. The last is 'the athletic dad' who is normally in his forties, married and has children. He typically goes for jawline, re-contouring, liposuction and small eyelift. It is asserted by many that men who opt for cosmetic surgery are driven by various reasons, among them being psychological reasons and the impact of men's body image dissatisfaction.

As for the social aspects, seeking cosmetic surgery by men is the result of an unfavorable sociocultural environment in terms of life style, depiction of beauty and cultural stereotyped values placed on it, and the societal projection of manhood either in local cultures or in the media. The latter in particular drives this point home through endless programs in television and internet that sanctify the images of 'stars', 'heroes' or 'divas', hence portraying an idealistic image of beauty. In a study on both genders conducted by a group of researchers in three hospitals in the region of Paris ${ }^{14}$ it has been explained that patients seeking cosmetic surgery are more anxious than the general population. ${ }^{15}$ The study asserts that patients lack self-confidence in society and seek improvement of self- esteem. They have a desire for social interaction and react to an emotional disturbance. It has also been concluded that social adjustment and acceptance was the main aim behind undergoing cosmetic surgery, as demonstrated in the respondents' answers to the question "What has the surgery brought to your life?", to which about $87 \%$ of the responses emphasized on the positive changes such as 'sense of well-being, greater self- confidence, joy or satisfaction, and even the increase of their chances of employment. ${ }^{16}$

It is a known fact that women's bodies in modern societies have become the locus of both increasing rates of obesity and body dissatisfaction. There is no doubt that both body image and excess weight can seriously impact women's physical and emotional health. The strong cultural value placed on thinness especially for women unfortunately may take precedence over health. ${ }^{17}$ Contemporary sociocultural environment is not just harmful but toxic in the aspect of body image as it is contributing to body dissatisfaction. In fact, women's bodies are overly exploited in many areas, such as the media in general, show business, fashion industry, advertisements, sex industry, beauty pageant competitions...etc and stereotyped beauty standards are rigidly defined regardless of race and culture.

However, men usually go for certain types of cosmetic surgery, among them 'body parts adjustment' and 'reshape for aesthetic aims'. In a study conducted by a group of researchers on 30 men who were seen for a cosmetic surgery between 1995 and 1997 at the University of Pennsylvania Medical centre, ${ }^{18}$ it was reported that men seek cosmetic interventions especially to adjust or reshape different body parts such as nose, eyes, and chin. The main reason that drove these men for this procedure was to look good or to reverse the effects of ageing. This same finding also corresponded with other studies. ${ }^{19}$ Therefore, liposuction, nose surgery, eyelid surgery, face lift and Male breast reduction are highly requested. ${ }^{20}$ Men also undergo other types of cosmetic surgery such as hair implant, penis enlargement, pectoral implants, testicular implants, in addition to other special cosmetic surgeries sought by trans-genders in particular.

\footnotetext{
${ }^{14}$ Meningaud JP BenadibaL Servanta JM , Herve C, Bertrand JC, PelicierY.., (2003). Depression, anxiety and quality of life: outcomes 9 months after facial cosmetic surgery. Cranio- Maxillofacial Surgery Article. [Internet] 2003 [cited 2016 May 10]. Available at http://www.ncbi.nlm.nih.gov/pubmed/12553927

${ }^{15}$ Ibid

${ }^{16}$ Ibid

${ }^{17}$ Marie -Claude Paquette \& Kim Raine (2004) Sociocultural Context of Women's Body Image. ElSevier, Social Science and Medicine 59 (2004) 1047-1058. Retrieved from

file:///C:/Users/Administrator/Documents/cosmetic\%20surgery\%20article\%204.pdfDate [15/2/2018]

${ }^{18}$ Michael J. Pertschuk. et al. (1998). Body Image Dissatisfaction in Male Cosmetic Surgery Patients.Aesthetic Plastic Surgery Article. [Internet] 1998 [cited 2016 May 10]. Available at

http://download.springer.com/static/pdf/306/art\%253A10.1007\%252Fs002669900160.pdf?originUrl=http\%3A\%2F\%2Flink. springer.com\%2Farticle\%2F10.1007\%2Fs002669900160

${ }^{19}$ Ibid

${ }^{20}$ Jerry Kennard. Plastic Surgery for Men.Article Doctor. [Internet] 2016 Mac 07 [cited 2016 Apr 10]. Available at https://www.verywell.com/male-cosmetic-surgery-2328548
} 


\section{Adolescents and Cosmetic Surgery}

Studies have shown that physical appearance is crucial to all people from different cultures, races, social classes and ages. However, adolescents are usually more concerned about their looks because of the many physical changes that occur during this period. According to his article "Ethics of Cosmetic Plastic Surgery in Adolescents", Michael A. Bernet explains "Teens as well as adults have valid cosmetic conditions that benefit from plastic surgery".

Adolescent cosmetic surgery is not new, but the topic has come to the forefront as a result of recent media attention". ${ }^{21} \mathrm{He}$ also clarified that "teens are often uncomfortable with their evolving bodies. Distortions in body appearance can lower self-confidence and disrupt social acceptance". ${ }^{22}$ Thus, we can conclude that going through puberty can give rise to amplified body concerns. The divide between the sexes can be appreciated when we consider that puberty for boys involves gaining characteristics typically admired by society, such as height, broadness, and strength. Puberty for girls brings with it changes that are usually less desirable, such as gaining curves and increased body fat. These changes may propagate increased body dissatisfaction among adolescent girls. The consequences of poor body image are dire, as studies have shown that "the effects of poor body image in children and adolescents... creates risk for the development of body image and eating disturbances as well as depression in adulthood". ${ }^{23}$ Obsession with body image -specifically body weight- may result in teenagers engaging in unhealthy habits such as restrictive dieting and excessive exercise, which paves the way to potentially dangerous disordered eating behaviours. Societal promotion of the thin ideal may also lead to prejudicial treatment, teasing or bullying of overweight youth.

With this in mind, it is not surprising that many teens opt for cosmetic surgery to correct these perceived imperfections and gain peace of mind. Statistics back this fact up, and The American Society of Plastic Surgeons (ASPS) estimates that "more than 333,000 cosmetic procedures were performed on patients 18 years of age or younger in the United States in 2005, compared to approximately 14,000 in $1996 " .{ }^{24}$ Also, according to theASPS (2008a), "224,658, 13-19 year olds underwent cosmetic surgery procedures in 2007 ". These trends are particularly prominent in developed countries, where the standards of living and income are high and the surgical techniques are cutting-edge. The most commonly performed surgeries are nose reshaping, ear surgery, breast augmentation, liposuction, chin augmentation, and abdominoplasty (tummy tucks), ${ }^{26}$ with breast augmentation and liposuction eliciting the most controversy. Also, according to Michael A. Bernet, "rhinoplasty (nose reshaping) ...is among the most requested surgical procedures for teenagers and, if done early, can prevent years of emotional distress". ${ }^{27}$

\footnotetext{
${ }^{21}$ Michael A. Bernet Ethics of Cosmetic Plastic Surgery in Adolescents, "AMA Journal of Ethics.Illuminating the Art of Medicine.Virtual Mentor. March 2005, Volume 7, Number 3. Retrieved from http://journalofethics.ama-assn.org2005/03/oped2-0503.html date [28/4/2017] ${ }^{22}$ Ibid

${ }^{23}$ Linda Smolak Body image in children and adolescents: where do we go from here? Elsevier Body image Journal Volume 1, Issue 1, January 2004, Pages 15-28 . Retrieved from http://www.sciencedirect.com/science/article/pii/S1740144503000081 date [ 28/4/2017]

${ }^{24}$ Diana Zuckerman , PhD \&Anisha Abraham M.D., M.P.h. Teenagers and Cosmetic Surgery: Focus on Breast Augmentation and Liposuction. Journal of Adolescent Health. October 2008Volume 43, Issue 4, Pages 318-324 Retrieved from http://www.jahonline.org/article/S1054-139X(08)00232-2/fulltext?cc=y date [28/4/2017]

${ }^{25}$ Charlotte N. Markey \& Patrick M. Markey .Correlates of Young Women's Interest in Obtaining Cosmetic Surgery. Sex Roles (2009) 61:158-166 DOI 10.1007/s11199-009-9625-5 Retrieved from http://download.springer.com/static/pdf/732/art\%253A10.1007\%252Fs11199-009-9625-

5.pdf?originUrl=http\%3A\%2F\%2Flink.springer.com\%2 Date 28/4/2017

${ }^{26}$ Diana Zuckerman, Ibid

${ }^{27}$ Michael A. Bernet Ethics of Cosmetic Plastic Surgery in Adolescents, Ibid.
} 
The question of whether undergoing cosmetic procedures improves body image and satisfaction in adolescents or not is still being debated. As of now, specific studies exploring the relationship between the two have not yet been carried out, according to Anisha Abraham et. al "there is no scientific evidence that surgery improves self-esteem or confidence in the long term," 28

And again "there are no well-designed studies that conclusively demonstrate that cosmetic surgery significantly improves body image for the surgically altered feature in the long term. Similarly, there are no conclusive studies that indicate that cosmetic surgery improves overall body image or quality of life for adolescents or adults". ${ }^{29}$ Rather, immediate physical benefits such as higher levels of energy and increased activity postliposuction, or reduced back pain after breast reduction surgeries, have been noted. The complications are those that arise due to cosmetic surgery at any age and are not specific to adolescents, such as botched lip fillers, burst and misplaced breast implants, and scarring post-liposuction.

\section{Conclusion}

Overall, it is safe to state that there has been a definite increase in the number of teenagers undergoing various cosmetic procedures and that a correlation can be drawn between this issue and poor body image, which can have alarming physical, social and emotional consequences. Thus, there is a need for further research on this issues and monitoring of this trend.

It is also concluded that regardless of the reasons for teenagers undergoing cosmetic surgery, these kinds of procedures have become an important trait of our modern life, and looking good is placed on the same pedestal as health. Teenagers from both sexes and of different cultural backgrounds (though it is more significant in developed countries) seek physical beauty, often pushed by psychological deficiencies such as body image distortion (BID) and delusional misperception, social factors and physical impairments. In their quest for personal and social acceptance for their looks, and despite the high cost and the risks, teenagers are willing to put their bodies under the knife and all the risks it entails. It is recommended that finding a good surgeon, good psychologist and counsellor is crucial, in order to avoid any potential complications, as both aspects; psychological and physical are equally important for accepting the outcomes of the cosmetic surgeries, if not to avoid them in the first place.

\section{References}

American Society of Plastic Surgeons. Men Fuel Rebound in Plastic Surgery: Sizeable Increases in Face Lift and other Surgical Procedures for Men. Doctor Article. [Internet] 2011 Apr 13 [cited 2016 May 10]. Available at http://www.plasticsurgery.org/news/2011/men-fuel-rebound-in-cosmetic-surgery-.html

Anisha Abraham M.D., M.P.H. and Diana Zuckerman Ph.D, Adolescents, Celebrity Worship, and Cosmetic Surgery, Journal of Adolescent Health, 2011-11-01, Volume 49, Issue 5, Pages 453-454. Retrieved from https://www.clinicalkey.com.ezp.imu.edu.my/\#!/content/journal/1-s2.0-S1054139X11003028

Charlotte N. Markey \& Patrick M. Markey .Correlates of Young Women's Interest in Obtaining Cosmetic Surgery. Sex Roles (2009) 61:158-166 DOI 10.1007/s11199-009-9625-5 Retrieved from http://download.springer.com/static/pdf/732/art\%253A10.1007\%252Fs11199-009-96255.pdf?originUrl=http\%3A\%2F\%2Flink.springer.com\%2 Date 28/4/2017

Christian Nordqvist. What is cosmetic surgery? What is plastic surgery? Article Doctor. [Internet], 2014 Sep 15 [cited 2016 May 10]. Available at www.medicalnewstoday.com/articles/155757.php

David A. Frederick, M. A. et al. Interest in Cosmetic Surgery and Body Image: Views of Men and Women across the Lifespan. Cosmetic Article.[Internet], 2007 Oct [cited May 10]. Available at http://journals.lww.com/plasreconsurg/Abstract/2007/10000/Interest_in_Cosmetic_Surgery_and_Body_I mage__Views.42.aspx

\footnotetext{
${ }^{28}$ Anisha Abraham M.D., M.P.H. and Diana Zuckerman Ph.D, Adolescents, Celebrity Worship, and Cosmetic Surgery, Journal of Adolescent Health, 2011-11-01, Volume 49, Issue 5, Pages 453-454. Retrieved from https://www.clinicalkey.com.ezp.imu.edu.my/\#!/content/journal/1-s2.0-S1054139X11003028

${ }^{29}$ Diana Zuckerman (2008), Ibid 
Diana Zuckerman , PhD \& Anisha Abraham M.D., M.P.h. Teenagers and Cosmetic Surgery: Focus on Breast Augmentation and Liposuction. Journal of Adolescent Health. October 2008Volume 43, Issue 4, Pages 318-324 Retrieved from http://www.jahonline.org/article/S1054-139X(08)00232-2/fulltext?cc=y date [28/4/2017]

Here's Why There's A 'Huge Boom' in Men Getting Plastic Surgery. Business insider Article. [Internet] 2014 [cited 2016 Apr 23]. Available at www.businessinsider,my/male-plastic-surgery-procedures-20142/?r=US\&IR=T\#ZYeGsXottTZwqed.97

Ishigooka,J., Iwao, M., Suzuki, M., Fukuyama, Y., Murasaki, M. and Miura, S. Demographic features of patients seeking cosmetic surgery. Psychiatry and Clinical Neurosciences Article. [Internet] 1998 [cited 2016 May 7]. Available at http://www.ncbi.nlm.nih.gov/pubmed/9681579

Jerry Kennard. Plastic Surgery for Men. Article Doctor. [Internet] 2016 Mac 07 [cited 2016 Apr 10]. Available at : https://www.verywell.com/male-cosmetic-surgery-2328548

Linda Smolak Body image in children and adolescents: where do we go from here? Elsevier Body image Journal Volume 1, Issue 1, January 2004, Pages 15-28 . Retrieved from

http://www.sciencedirect.com/science/article/pii/S1740144503000081 date [ 28/4/2017]

Marie -Claude Paquette \& Kim Raine (2004) Sociocultural Context of Women's Body Image. ElSevier, Social Science and Medicine 59 (2004) 1047-1058. Retrieved from file:///C:/Users/Administrator/Documents/cosmetic\%20surgery\%20article\%204.pdf Date [15/2/2018]

Meningaud JP BenadibaL Servanta JM , Herve C, Bertrand JC , PelicierY.., (2003). Depression, anxiety and quality of life: outcomes 9 months after facial cosmetic surgery. Cranio- Maxillofacial Surgery Article. [Internet] 2003 [cited 2016 May 10]. Available at http://www.ncbi.nlm.nih.gov/pubmed/12553927

Michael A. Bernet Ethics of Cosmetic Plastic Surgery in Adolescents, "AMA Journal of Ethics.Illuminating the Art of Medicine.Virtual Mentor. March 2005, Volume 7, Number 3. Retrieved from http://journalofethics.ama-assn.org/2005/03/oped2-0503.html date [28/4/2017]

Michael J. Pertschuk. et al. (1998). Body Image Dissatisfaction in Male Cosmetic Surgery Patients.Aesthetic Plastic Surgery Article. [Internet] 1998 [cited 2016 May 10]. Available at

http://download.springer.com/static/pdf/306/art\%253A10.1007\%252Fs002669900160.pdf?originUrl=http\%3A \%2F\%2Flink.springer.com\%2Farticle\%2F10.1007\%2Fs002669900160

Onkvisit, S., \& Shaw, J. (1987). Self-concept and image congruence: Some research and managerial implications. Journal of Consumer Marketing, 4, 13-23

Peter David Slade. (1993). Invited Essay; What is Body Image. Elsevier Science Article. [Internet] 1993 [cited 2016 May 10]. Available at http://www.freepaperdownload.us/1773/Article2888653.htm

Phaedrus by Plato. Retrieved from http://sfbay-anarchists.org/wp-content/uploads/2013/07/Plato-Phaedrus.pdf . Date:[6/2/2018]

The Concept of Beauty in Ancient Egypt. Retrieved from: http://www.ancientfacts.net/the-concept-of-beauty-inancient-egypt/ . Date: [6/2/2018]

Umberto Eco, History of Beauty. Rizzoli International Publications, Incorporated, 2010 